\title{
THE USE OF RADIOACTIVE IODINE IN STUDYING THE PATHOLOGIC PHYSIOLOGY OF THYROID DISEASE
}

\author{
By RULON W. RAWSON
}

(From the Memorial Hospital and the Sloan-Kettering Institute, New York City)

It was in May, 1938 that Hertz et al. (1) published the first report on biological studies with a radioactive isotope of iodine. By today's standards these first studies were done under the least favorable conditions with an isotope whose half life of 25 minutes limited the studies that could be done. Notwithstanding the limitations put on these investigators they not only reaffirmed certain principles of thyroid physiology, but with other investigators, Hamilton (2), Hamilton and Soley (3), and LeBlond and Süe (4), who began working with radioactive isotopes of iodine in other laboratories at about the same time, they pioneered in a new field of investigating the thyroid. Today we have a small army of investigators bringing together a variety of disciplines, i.e., physics, chemistry, embryology, physiology, histochemistry, pathology and clinical medicine in studying with radioactive iodine and other tools normal and morbid physiology of the thyroid. Many of these investigators are students whose primary interests are related to studies of normal and abnormal function of the thyroid. These students are delighted to have made available so many new technics with which to increase our knowledge of thyroid physiology. Many of the investigators in this field are interested primarily in isotopic methods and their application to studies in biology. They probably have been attracted to this field because of the unique avidity of the thyroid for iodine which makes this an ideal tissue for applying isotopic methods, and for studying the biologic effects of irradiation with such isotopes.

At the present time, it seems quite proper to ask questions such as those posed by Dr. William T. Salter preceding the 1948 Symposium on Radio Iodine at the Brookhaven National Laboratory. "1. How has radio iodine improved our knowledge of iodine metabolism and of the physiology and the therapy of the thyroid? 2. How do the results harmonize with past experience?" The purpose of this paper is to review the contributions made to our knowledge of human thyroid disease by studies with radioactive iodine.

The earliest studies done at the clinical level by Hamilton and Soley (3) reaffirmed our previous concepts that the human thyroid has an avidity for iodine. These investigators compared the collection by the thyroid of iodine labelled with radio iodine and its excretion in the urine and feces in normal subjects and in patients having various thyroid disorders. They found that an orally administered dose of labelled iodine was absorbed rapidly and could be detected in the thyroid within 20 minutes. In normal subjects 74 to 89 per cent of the dose was excreted during a five-day period with the major portion appearing during the first 24 hours. Two myxedematous patients excreted 91 and 94 per cent in the urine during five days but at a much slower rate than did the normals. Thyrotoxic patients previously treated with iodine excreted about the same amount of iodine as did normal individuals. Fecal excretion of these labelled doses of iodine averaged only about 1 per cent of the dose. In another series of studies Hamilton and Soley (5) recorded the characteristic collection curves obtained by in vivo measurements for various thyroid states. The curve that they observed to be typical for normal thyroids was a smooth curve which leveled off to a flat plateau in two days. The initial collection by thyroids of hyperthyroid patients was greater and much more rapid than in normal thyroids but decreased almost as rapidly to a plateau lower than that of the normal thyroids. This phenomenon was also observed in two goiterous hypothyroid children (Hamilton, et al. [6]). This rapid decrease to a lower than normal plateau following an increased pickup observed in the goiterous children and hyperthyroid individuals might be attributed to the fact that these investigators were using $14 \mathrm{mgm}$. of inert iodide as carrier. This concept is supported by their failure to observe the rapid loss of radio iodine from the thyroid when a carrier dose of $0.1 \mu \mathrm{g}$. of sodium iodide was given. 
This explanation is further supported by the observations of Hertz et al. (7) who administered radioactive iodine with varying amounts of carrier iodide to patients suffering with Graves' disease at varying stages of preoperative treatment with potassium iodide. They observed that the untreated hyperplastic thyroids of Graves' disease collected 80 per cent or more of the labelled iodine if the dose was small. They also observed that with increasing time intervals after the administration of isotopic iodine there was an increasing amount of radioactive iodine in the thyroxine-like fraction of the gland.

Since these comparatively earlier observations, a number of investigators have used isotopic technics in studying the role of iodine in normal and abnormal thyroid physiology.

Chapman et al. (8) have studied the collection of radio iodine by the human fetus. They administered tracer doses of $\mathrm{I}^{131} 12$ to 48 hours before operation to pregnant women who because of organic disease were coming to therapeutic abortion. The intact fetus was fixed in formalin and then sectioned longitudinally, one half was taken for measurements of radioactivity and the other half was examined histologically. They observed that fetuses less than 12 weeks old did not concentrate any measurable amount of labelled iodine. In those fetuses which varied in age from 14 to 32 weeks the thyroids showed an avidity for iodine which seemed to increase with the age of the fetus. It is of interest that these investigators were able to confirm the opinion that the onset of function as measured in this manner is correlated with the appearance of definite follicles containing colloid.

Astwood and Stanley (9) studied the rate of accumulation of radioactive iodine by the thyroid in 70 normal humans. By plotting the counting rate per second obtained at a standard distance from the thyroid against the square root of the elapsed time in minutes they were able to plot a straight line which continued for about eight hours from which they were able to determine an accumulation gradient. In normal humans they found this accumulation gradient to vary between the limits of 1.5 and 36.4 with a mean of 9.3. Myxedematous patients were found to have accumulation gradients of 0.5 to 1.9 and thyrotoxic patients receiving no treatment at the time of testing were found to have gradients which varied between 17.0 and 43.6.
Keating et al. (10) followed the rate of radioactive iodine excretion in patients who had received 100 microcuries of $\mathrm{I}^{131}$ with $100 \mu \mathrm{g}$. of carrier iodine. By mathematical analysis their urinary excretion curves yielded four quantities: 1 . The renal fraction (that fraction of the dose excreted in the urine); 2 . The disappearance rate (the proportional rate of disappearance from the blood) ; 3. The renal excretion rate; and 4 . The collection rate (the proportional rate of disappearance into other sites than the kidneys which they interpreted as an index of thyroid collection rate). They found the renal fraction to be greater than normal in hypothyroid patients and less than normal in hyperthyroid patients. The disappearance rates they found to be less in hypothyroid patients and markedly greater than normal in patients having hyperthyroidism. The most significant variation that they observed was in the collection rates which were much less than normal in hypothyroid states and averaged six times the normal in hyperthyroid patients.

These marked variations from normal in the collection of iodine by the thyroid or the urinary excretion of radio iodine in hypothyroidism and in hyperthyroidism have prompted many investigators to use such methods of study as a means of diagnosing abnormal states of thyroid function. Quimby and McCune (11), who used in vivo measuring technics, found that children who clinically were euthyroid concentrated and retained in their thyroids about 12 per cent of an administered dose of radio iodine. They found that hyperthyroid children concentrated and retained several fold the value obtained in euthyroid children whereas hypothyroid children concentrated as little as 1 per cent or less of the dose. McArthur et al. (12) followed the urinary excretion of radio iodine in a series of patients and observed the urinary excretion of 22 thyrotoxic patients to average 25 per cent; of 30 non-thyrotoxic patients to average 60 per cent. They reported that this method of study was of real value in excluding the diagnosis of Graves' disease in patients having hypermetabolism due to alcoholism, anxiety, compensated hypertensive cardiovascular disease, Parkinsonism, pheochromocytoma and thyrotoxicosis factitia.

Feitelberg et al. (13) have described a method for measuring and recording localized collections 
of radio iodine. It is of interest that with this method they were able to demonstrate a functioning lingual thyroid.

Werner et al. $(14,15)$, have used in vivo methods for determining the per cent concentration and retention of radio iodine by the thyroid. They reported that the uptake by normal thyroid tissue is 20 to 30 per cent of the administered tracer and that any uptake of 40 per cent or more is regarded by them as diagnostic of hyperthyroidism.

Skanse and Riggs (16) reported that with radioactive iodine tracer studies they were able to make the diagnosis of thyrotoxicosis factitia in two patients who had elevated basal metabolic rates and abnormally high serum precipitable iodines. Both of these patients excreted more than 97 per cent of the radio iodine and by in vivo measurements were found to concentrate none in their thyroids. Rawson and Skanse (17) have called attention to the fact that thyrotoxic patients who have previously received "priodax" for $\mathrm{x}$-ray visualization of the gall bladder excrete most of the radio iodine given within an indefinite period of time following cholecystography. Such patients, if clinically thyrotoxic, on the basis of elevated serum precipitable iodines and maximum excretion of radio iodine might be confused with patients having thyrotoxicosis factitia. This problem should be a rare one if careful physical examinations are done. In thyrotoxicosis factitia the thyroid should not be enlarged or it may be so atrophic, as the result of the ingested thyroid, as to be impossible to feel, whereas in classic Graves' disease the thyroid can be felt without any trouble by an experienced examiner.

The above studies have provided base lines which have been useful in evaluating the effect on the thyroid of various thyroid-stimulating or thyroid-inhibiting agents. They have also provided standards for certain studies which may throw light on such questions as to the genesis of nontoxic goiters in the presence of an adequate intake of iodine, the mode of action of iodides in Graves' disease, and as to the mechanism of action of the thyroid hormone.

Stanley and Astwood (18) have evaluated the effect of thyroid-stimulating hormone on the collection of radio iodine by the thyroids of normal humans. They determined the accumulation gradients in the thyroids of their subjects and followed the effect of thyroid-stimulating hormone on these gradients. They observed that for eight hours after the injection of hormone no effect on the rate of iodine pickup could be detected, but thereafter a marked acceleration which became maximum in 24 to 48 hours occurred. This increased avidity for iodine observed in subjects after administering thyrotrophic hormone was not altered by administering mercaptoimidazole, an agent which effectively inhibits the binding of iodine to thyroid protein, $i$. $e$, inhibits the iodination of thyroid hormone. This observation suggests that notwithstanding the mode of action of the thyroid-stimulating hormone, the increased rate of collection of iodide by the thyroid is not secondary to its being converted to thyroid hormone. Indeed it may be suggested on the basis of this observation that thyrotropic hormone has increased the iodide space of the thyroid and that any increased thyroid hormone production following treatment with thyrotrophic hormone is secondary. They were unable to demonstrate any loss of stored iodine following the administration of thyrotrophic hormone. These results differ from those obtained by Keating et al. (19), who studied the effect of thyroidstimulating hormone on the collection and release of radio iodine by the thyroids of chicks. These investigators observed a loss of iodine from the chick thyroid before any increased collection could be demonstrated. These differences might be explained as species differences or they might be related to dose levels. If one calculates the doses per unit weight of test animal, the chicks received doses 20 to 40 times greater than those received by the human subjects.

Stanley and Astwood (18) also observed that patients who were considered to have potentially normal thyroids and who were taking desiccated thyroid were incapable of accumulating significant amounts of radio iodine in their thyroids. They did observe, however, that patients who had been taking desiccated thyroid up to the time of receiving the thyrotrophic hormone were capable of concentrating radio iodine after thyroid-stimulating hormone had been administered. This inhibition to the iodine concentrating capacity of the thyroid by the administration of exogenous thyroid hormone might be attributed to an inhibition of thyrotrophic hormone production in the subject's own pituitary. It must be pointed out, 
however, that Cortell and Rawson (20) have demonstrated that thyroxine when administered to hypophysectomized rats partially inhibits the action of administered thyroid-stimulating hormone on the thyroid. It would be interesting to compare the effects of thyroid-stimulating hormone on the accumulation gradients of radio iodine in the same euthyroid subjects before and after treatment with desiccated thyroid. Stanley and Astwood (18) suggest that this method of 'study might be of value in determining whether or not a patient being treated with desiccated thyroid does or does not have a potentially functional thyroid gland.

Studies with radioactive iodine have been of value not only in determining the mode of action of certain thyroid-inhibiting agents but such studies have also been of value in quantitating the effects of a variety of these drugs. In 1943 Rawson et al. (21) reported a patient who had developed a large goiter, while taking potassium thiocyanate in treatment of hypertension. Biopsy of this gland showed an extreme hyperplasia. Only a small per cent of a tracer of $\mathrm{I}^{131}$ given to this patient was excreted in the urine. Unfortunately this observation was not correlated with the blood thiocyanate level.

Subsequent studies by Haines (22) and by Richards (23) done in several patients having "thiocyanate goiter" have revealed that the excretion of radioactive iodine by such goiterous patients can be related to the blood thiocyanate levels observed in such patients. If the thiocyanate level is elevated, most of the iodide is excreted; if it is low, less of the iodide is excreted.

Rawson et al. (24) used radio iodine tracer technics in evaluating the action of thiouracil on the thyroids of Graves' disease. They prepared patients for thyroidectomy by administering thiouracil. Preoperatively they gave ten of their patients tracer doses of $\mathrm{I}^{131}$ and determined the radioactive iodine excreted in the urine and that recoverable in the operatively removed thyroids. They found that most of the tracer iodine was excreted in the urine and that only a small per cent was contained in the thyroids. They concluded that this drug acted to interfere with the synthesis of thyroid hormone by setting up a block to the collection or the utilization of iodide.

Studies done by Stanley and Astwood have demonstrated that in thyrotoxic humans the thiouracil group of drugs causes an inhibition to the organic bindings of iodine (which must first have been accumulated by the thyroid as iodide) to thyroid protein. By measuring with in vivo methods the pickup of radio iodine by the thyroid they were able to demonstrate that the thyroid, though well controlled by the administered drug, was capable of concentrating iodide in the thyroid. That this collected $\mathrm{I}^{131}$ existed as iodide in the wellcontrolled gland was evidenced by the fact that the administration of large doses of potassium iodicle resulted in a sudden decrease in the activity over the thyroid. They also demonstrated that the administration of potassium thiocyanate resulted in a prompt discharge of accumulated iodide from the thyroid. It is interesting that bromide was observed by these investigators to have no effect on the collected iodide. Patients receiving thiouracil or related agents in doses inadequate to control their thyrotoxicosis when injected with potassium thiocyanate were found to discharge only a fraction of the accumulated radio iodine and were concluded to be receiving inadequate amounts of the drug to inhibit the binding of iodine to the thyroid protein. It has been suggested by Stanley and Astwood (25) that this method of study would be of value in determining the adequacy of dose in patients undergoing treatment with any of these agents. On the basis of these observations it is apparent that the first step in storing iodine in the thyroid is that of concentrating it as iodide in an iodide space or trap. It would appear from these studies that the pickup of iodide is not dependent upon the rate of iodination of the hormone. On the other hand we have observed that the pickup of iodine by the thyroids of rats under the influence of thiouracil is only a fraction of that collected by thyroids of untreated controls even at 10 minutes after administering the tracer iodine. Notwithstanding this demonstration that the iodine is first concentrated as iodide we still do not understand the mechanism by which the iodicle is accumulated in the thyroid nor are we able to explain the increased avidity for iodine by the hyperplastic thyroids of Graves' disease nor by the thyroids of animals previously treated with thyrotrophic hormone.

Stanley and Astwood (26) have compared and quantitated the thyroid-inhibiting properties of 
several goitrogenic agents on the thyroids of human subjects. The method that they used depended on the capacity of these agents to modify the accumulation gradients of radioactive iodine by the thyroids as detected by serial counts with an externally placed Geiger-Mueller counter. The values obtained by these investigators are considerably different from those obtained by methods which depend upon the goitrogenic effects of these drugs in rats. For example, whereas propyl thiouracil has goitrogenic properties in the rat which are 10 times those of thiouracil, by this method of assay propyl thiouracil has only 0.75 the activity of thiouracil. Likewise, thiourea, an agent possessing only 0.1 the goitrogenic activity of thiouracil in the rat is equally as effective as thiouracil in altering the accumulation gradient in human thyroids.

Rawson and McGinty $(27,28)$, who compared the minimal doses of various injected drugs necessary to inhibit significantly the concentration of radioactive iodine in the chick thyroid found that propyl thiouracil was no more effective than thiouracil whereas by tests of goitrogenesis in the rat propyl thiouracil was 10 times more active than thiouracil. These same investigators found that benzyl thiouracil was 10 times as effective as thiouracil in inhibiting the concentration of radioactive iodine in the thyroid of a chick. Stanley and Astwood (26) found this agent in their studies on the human to have 0.75 the activity of thiouracil. McGinty and Wilson (29) have applied the methods of Stanley and Astwood in quantitating the effects of these agents on the thyroids of the Rhesus monkey. They have found the monkey thyroid to respond like the human thyroid, both qualitatively and quantitatively to these various thyroid-inhibiting agents. On the basis of these observations we might suggest then that agents would best be quantitated on the monkey with the method described by Stanley and Astwood before being subjected to clinical trial in the human by the same method. The final test of clinical usefulness will depend of course upon testing such drugs on patients having thyrotoxicosis. The need for this final test is demonstrated by our own observations that benzyl thiouracil, which when tested in the rat and the chick seemed to be a very active agent and when tested by the method of Stanley and Astwood had about the same activity as propyl thiouracil, was ineffective in controlling thyrotoxicosis in a small series of patients.

The mechanism by which the various salts of iodine exert their well-known therapeutic effect in Graves' disease has long remained unexplained. Indeed when one considers that the thyroid of untreated Graves' disease has an increased avidity for iodine which it rapidly converts and secretes into the circulation as thyroid hormone, the administration of iodine to such patients would seem to be an unwise maneuver. However, notwithstanding these theoretical contraindications, the therapeutic value of iodine in Graves' disease is a well-established fact. Plummer (30) who established the value of this therapeutic measure advanced the hypothesis that the toxic effects of Graves' disease were due to the elaboration of an incompletely iodinated hormone molecule. $\mathrm{He}$ suggested that the therapeutic action of iodine in this disease resulted from complete iodination of the hormone which even in excess was less toxic than the abnormal hormone.

In contrast to the two-hormone theory advanced by Plummer (30), Rawson et al. (31) have advanced a theory that iodine has two actions on the thyroid, an iodinating or a nutritive action and an involuting action on the thyroid of Graves' disease and have reported that they had been able to separate these two actions of iodine on the thyroid. They studied patients having Graves' disease before any medication was given, after treatment with thiouracil had caused a fall in the basal metabolic rate to a normal level, and after iodine had been added to the regime of treatment with thiouracil. Observations included micro-histometric studies of biopsy specimens taken before treatment, after treatment with thiouracil, but before administering iodides, and of glands removed at operation after treatment with both drugs. The urinary excretion of radioactive iodine was determined before and during treatment with thiouracil. Total and thyroglobulin iodines were determined in the operatively removed thyroids. The results showed hyperplasia of the thyroid samples removed before starting treatment with mean acinar cell heights which averaged 12.0 micra. There was an increase in thyroid hyperplasia after treatment with thiouracil, the mean acinar cell heights averaging 13.9 micra. However, involution was observed after iodine had been adminis- 
tered in addition to thiouracil, the average mean acinar cell height decreasing to 7.2 micra. This involution occurred even though the thyroids were not utilizing the iodine in the synthesis of thyroid hormone as evidenced by urinary excretions of radio iodine during treatment with thiouracil which averaged 80 per cent as contrasted to average radio iodine excretions of 25 per cent before beginning treatment. The failure of such glands to utilize iodine in the synthesis of thyroid hormone is further supported by the thyroglobulin iodine values which in the glands taken from patients who had received thiouracil and iodine averaged $7.0 \mathrm{mgm}$. $100 \mathrm{gm}$. of fresh thyroid tissue. The average thyroglobulin iodine of a comparable series of patients who had been prepared for operation with thiouracil alone was $6.8 \mathrm{mgm}$./
$100 \mathrm{gm}$. of fresh thyroid tissue, of normal human thyroids $29.8 \mathrm{mgm}$. per cent, of a small series of patients treated with iodine only. $36.6 \mathrm{mgm}$. per cent.

All of the iodine administered to one patient was labelled with radioactive iodine and thus a balance study was made. Before treatment only 16.3 per cent of a tracer dose was excretecl. After treatment with thiouracil $0.8 \mathrm{gm}$. daily for 15 days, 73.5 per cent of an identical dose of radio iodine was excreted. Following the second biopsy taken from the thyroid, a daily dose of $300 \mathrm{mgm}$. of sodium iodide labelled with 100 microcuries of radioactive iodine was administered in addition to thiouracil $0.8 \mathrm{gm}$. daily. The radioactivity demonstrated in the urine excreted during and after the 10 clay period of treatment with thiouracil and

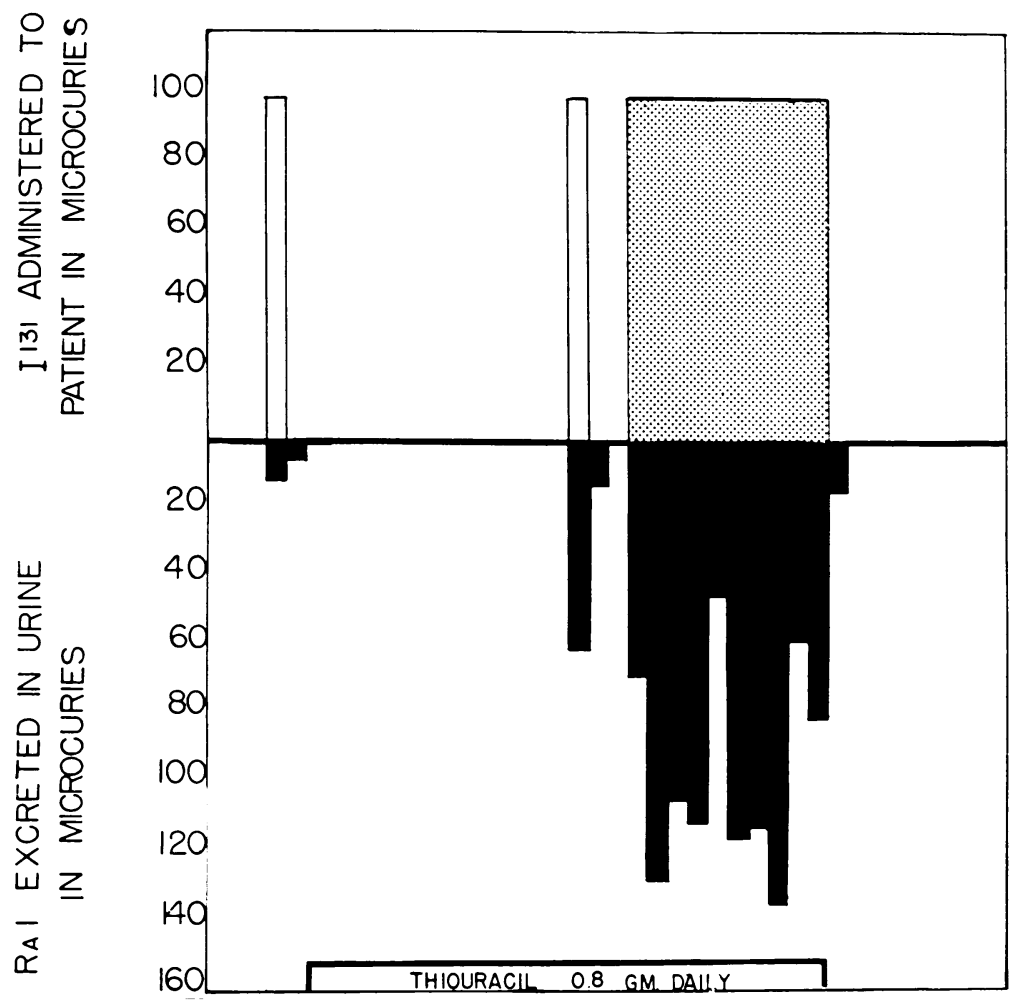

Fig. 1. Radio Iodine Balance in Patient Before Treatanent with Thiocracil, Dering Treatment with Thiolracil and Dering TreatMext With Thiolkacil. Axd Sodum Iodine

Intake above the line. Urinary excretion below. With regard to intake plain white columns indicate that tracer iodine was given with a carrier of 150 gamma of non-radioactive sodium iodide. Stippled columns indicate that radioactive iodine was given as tracer for therapeutic dose of $300 \mathrm{mgm}$. daily of ordinary sodium iodide. (From Rawson, Moore. Peacock, Means, Cope and Riddell, J. Clin. Invest., 1945, 24, 875.) 
labelled sodium iodide practically equalled the radioactivity administered. See Figure 1 . The radioactivity demonstrated in this patient's operatively removed thyroid was too little to measure and the thyroglobulin iodine value was only $2.3 \mathrm{mgm}$. per cent. Notwithstanding the fact that this gland failed to accumulate or to convert the administered iodine to thyroglobulin, the thyroid tissue examined after treatment with sodium iodide was well involuted in contrast to an extreme hyperplasia observed in the biopsy specimen taken just before adding iodine to the treatment. See Figure 2. This separation of the involuting action of iodine from its nutritive action, these investigators believe, may explain the paradoxical effect of iodine in Graves' disease. They also suggested that the involuting effect of iodine in Graves' disease was due to an inhibitory action of this agent to the action of thyrotrophic hormone on the thyroid cell.

Space will not permit further discussion as to the mechanism of this involuting action of iodine on the thyroid. However, attention should be called to the reports of Wolff and Chaikoff (32), who by using tracer technics have demonstrated in rats that the maintenance of an inorganic blood iodide level of $200 \mu \mathrm{g}$. per cent or more interferes with the organic binding of iodine by the thyroid. They suggest that the level of plasma iodide is part of a homeostatic mechanism which governs hormone synthesis in the normal gland.

Although there is good evidence that endemic goiter is due to a deficiency of iodine intake, it is difficult to explain the development of such nontoxic goiters in certain patients who apparently have an adequate intake of iodine. Many students of thyroid disease have suspected the existence of positive goitrogens which play a role in the development of some of the non-toxic goiters developing in subjects whose iodine intakes by accepted standards are more than adequate. Greer and Astwood (33) have demonstrated that certain foods have an inhibitory effect to the accumulation of radio iodine. They have evaluated the effects of 61 different food substances on the "accumulation gradient" of radio iodine in normal hu-

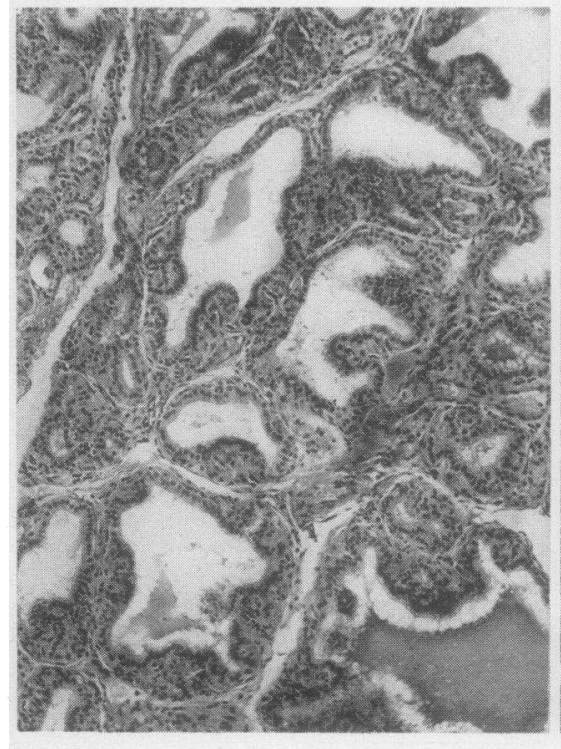

A

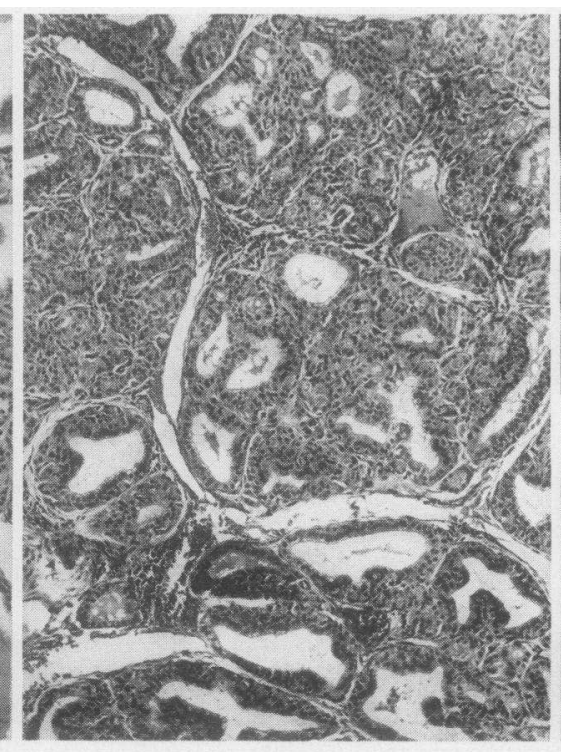

B

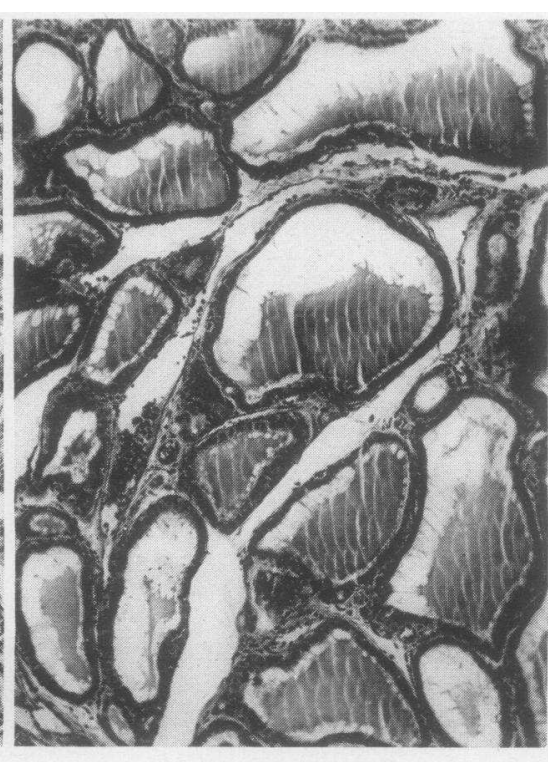

C

Fig. 2. Histologic Sections Taken From Biopsy Specimens and Operatively Removed Thyroid in Patient Treated with Thiouracil and Thiouracil Plus Sodium Iodide

A. Histologic section of biopsy specimen taken before any treatment. Mean cell height $15.3 \pm 0.14$.

B. Histologic section of biopsy removed after treatment with thiouracil had caused a fall in the B.M.R. to a euthyroid level. Mean cell height $17.3 \pm 0.17$.

C. Histologic section of operatively removed thyroid after treatment with thiouracil and iodide. Mean cell height 10.3 \pm 0.07 .

(From Rawson, Moore, Peacock, Means, Cope and Riddell, J. Clin. Invest., 1945, 24, 873.) 


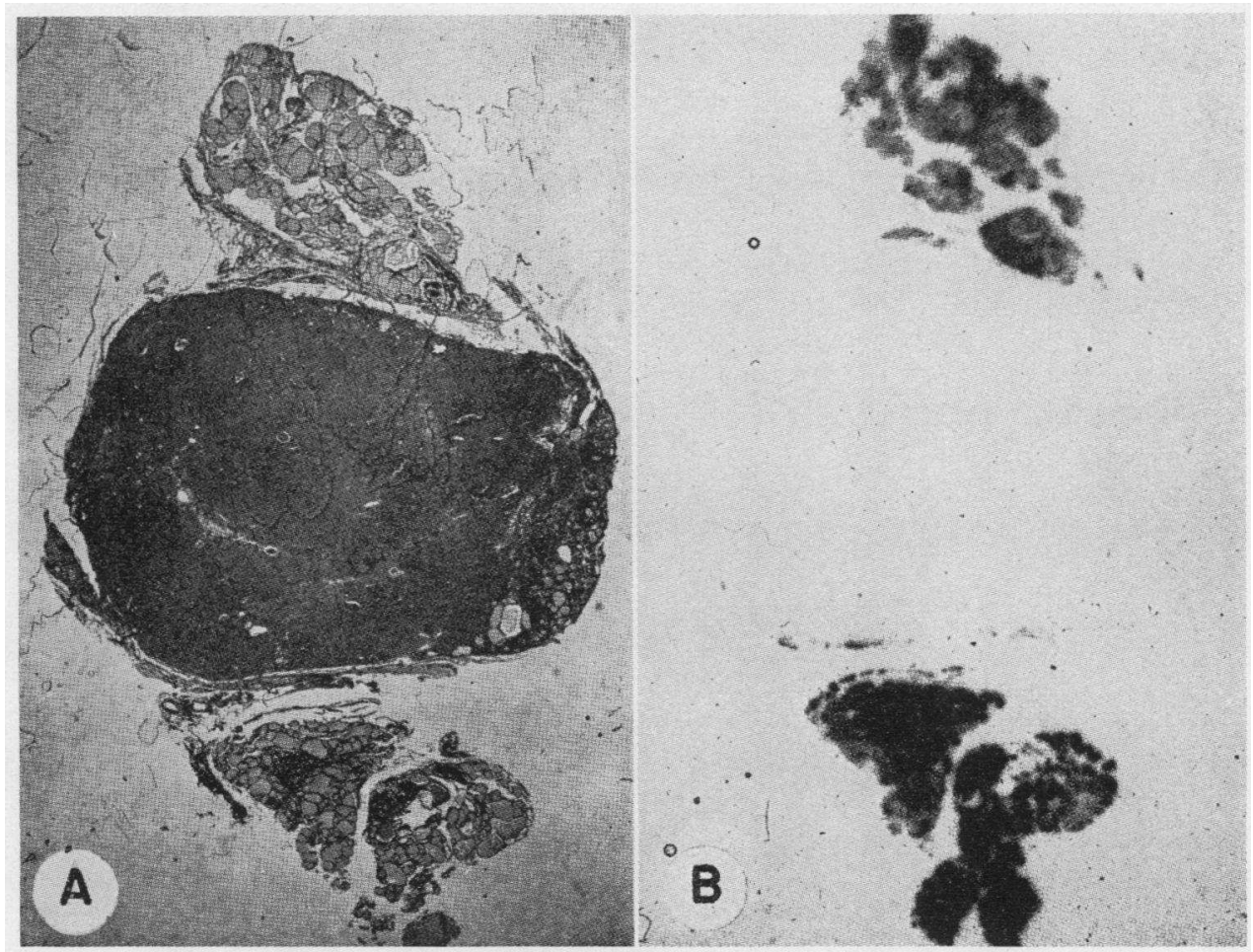

Fig. 3. A Solid Cellular or Trabecular Adenoma Surrounded by Normal Thyroid Tissue with Autoradiogram

A. Histologic section.

B. Autoradiogram showing no evidence of function in the adenoma. The areas of black coincide with the normal thyroid tissue.

(From Dobyns and Lennon, J. Clin. Endocrinol., 1948, 8, 735.)

man thyroids, and have observed that the more active foods in inhibiting the thyroid's accumulation of radioactive iodine are rutabaga, turnips, string beans, frozen peaches, pears, peanuts, walnuts, liver, milk and oysters. On the basis of these studies we might suggest that the sporadic goiters seen in areas where the iodine intake is adequate are related to positive goitrogens contained in certain dietary products.

Radioactive iodine has been a most valuable tool in evaluating the function of certain tumors of the thyroid. Indeed studies with radioactive iodine have stimulated an interest in neoplasms of the thyroid, benign and malignant, that has probably never existed before. The benign tumors of the thyroid have been studied extensively by Cope et al. (34), Rawson et al. (35), and by Dobyns and Lennon (36). In general it can be said that the benign tumors have an avidity for radio iodine which can be correlated with the degree of histologic differentiation. The solid cellular tumors, trabecular and tubular adenomas, which show 110 differentiation have been found to manifest practically no iodine concentrating capacity whereas the microfollicular adenomas which show definite but incomplete differentiation have been observed to have an avidity for iodine approaching that of normal thyroid tissue. See Figures 3 and 4 . At the other end of the spectrum single adenomas have been found in patients having hyperthyroidism which was relieved by simple removal of the adenoma plus a biopsy specimen of uninvolved tissue. In these instances the radio iodine was found concentrated in the adenoma and none in the uninvolved tissue. Such tumors presented histologic pictures of hypertrophied microfollicular adenomas or frank hyperplasia. The surrounding uninvolved tissue showed hyperinvolution or decreased acinar cell heights.

Dobyns and Lennon (36) attempted to correlate the cell heights of these adenomas with their capacities to concentrate radio iodine. They found 


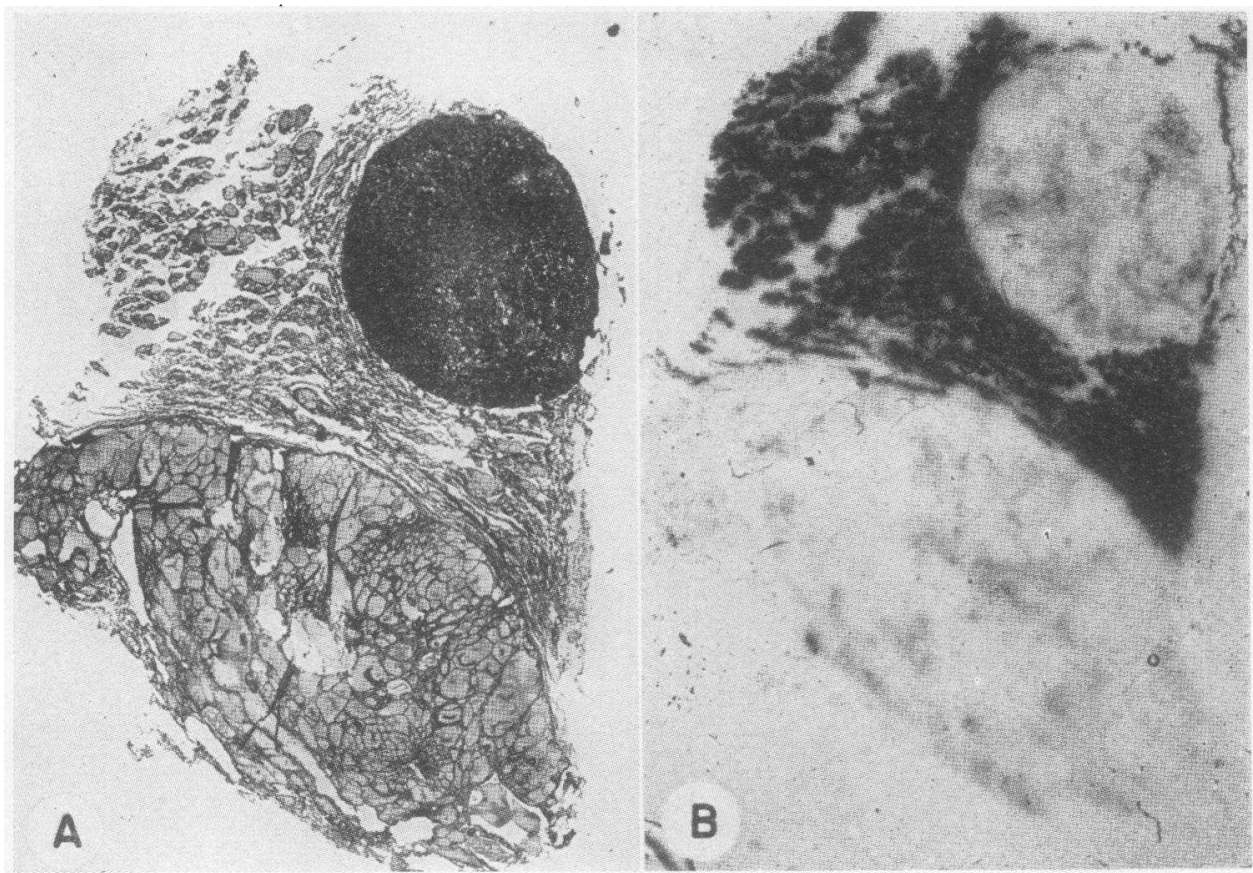

Fig. 4. Two Functional Adexomas of the Thyroid Separated by Normal Thyroid Tissue

A. Histologic section. Adenoma above is tubular and microfollicular; below is a micro et macrofollicular adenoma which has certain characteristics suggestive of a colloid adenoma.

B. Autoradiogram in which both adenomas were observed to have low-grade iodine concentrating capacity, but much less than that observed in the areas corresponding to the normal thyroid tissue between the two adenomas.

(From Dobyns and Lennon, J. Clin. Fndocrinol., 1948, 8, 738.)

a certain group of hyperplastic adenomas which did not concentrate radio iodine. Such tumors showed a marked variability in their cell heights and as such resembled a group of papillary adenocarcinomas. See Figure 5. The tumors which were functioning in excess of the surrounding thyroid tissue were found to have mean cell heights significantly and uniformly in excess of the surrounding normal thyroid tissue. See Figure 6. They not only found hyperfunctioning adenomas as evidenced by an increased pickup of radio iodine, which were associated with clinical hyperthyroidism, but they also found certain small adenomas which concentrated more radio iodine and had uniformly increased cell heights as compared to the surrounding tissue in patients who had no elevation in the basal metabolic rates. Continuation of such studies may throw considerable light on the life history of hyperfunctioning adenomas of the thyroid as well as upon the history of certain papillary adenocarcinomas.
Studies of cancer of the thyroid with radioactive iodine have not only excited an unprecedented interest in this clisease, but they have already resulted in a much better understanding of the biology of this type of cancer. Furthermore, this writer believes these studies have already led to improvements in treatment of this disease with the conventional forms of therapy. Hamilton et al. (37) were the first investigators to apply radio iodine methods in studying cancer of the thyroid. With autoradiographic technics they demonstrated that normal thyroid tissue concentrated labelled iodine in the thyroid follicle. With this same technic they studied two cancers of the thyroid and observed that the cancerous tissue was incapable of concentrating any radio iodine. The first successful attempt to demonstrate pickup of radioactive iodine by thyroid cancer was reported in 1942 and 1944 by Keston et al. (38) and by Frantz et al. (39). They administered tracer doses of radio iodine to three patients having thy- 
roid tumors with bony metastases. One bony metastasis from one of these tumors, an adenoma malignum, showed an appreciable uptake of radio iodine.

In 1946, Leiter et al. (40) reported two cases of adenocarcinoma with functioning metastases and hyperthyroidism which they studied with radioactive iodine. One of these patients had been totally thyroidectomized in 1923. Tracer studies with radioactive iodine done in this patient demonstrated that there was no functioning thyroid tissue in the neck and that the source of hyperthy- roidism was in the metastatic tumors. Seidlin et al. (41) have reported that treatment of this patient with radioactive iodine resulted in definite and lasting improvement.

Following these observations several investigators interested in using radio iodine in the therapy of cancer of the thyroid have undertaken studies with radio iodine concerning the natural avidity of various thyroid cancers for radio iodine and means of increasing the capacity of such tumors to concentrate radioactive iodine.

Marinelli et al. (42) have investigated with
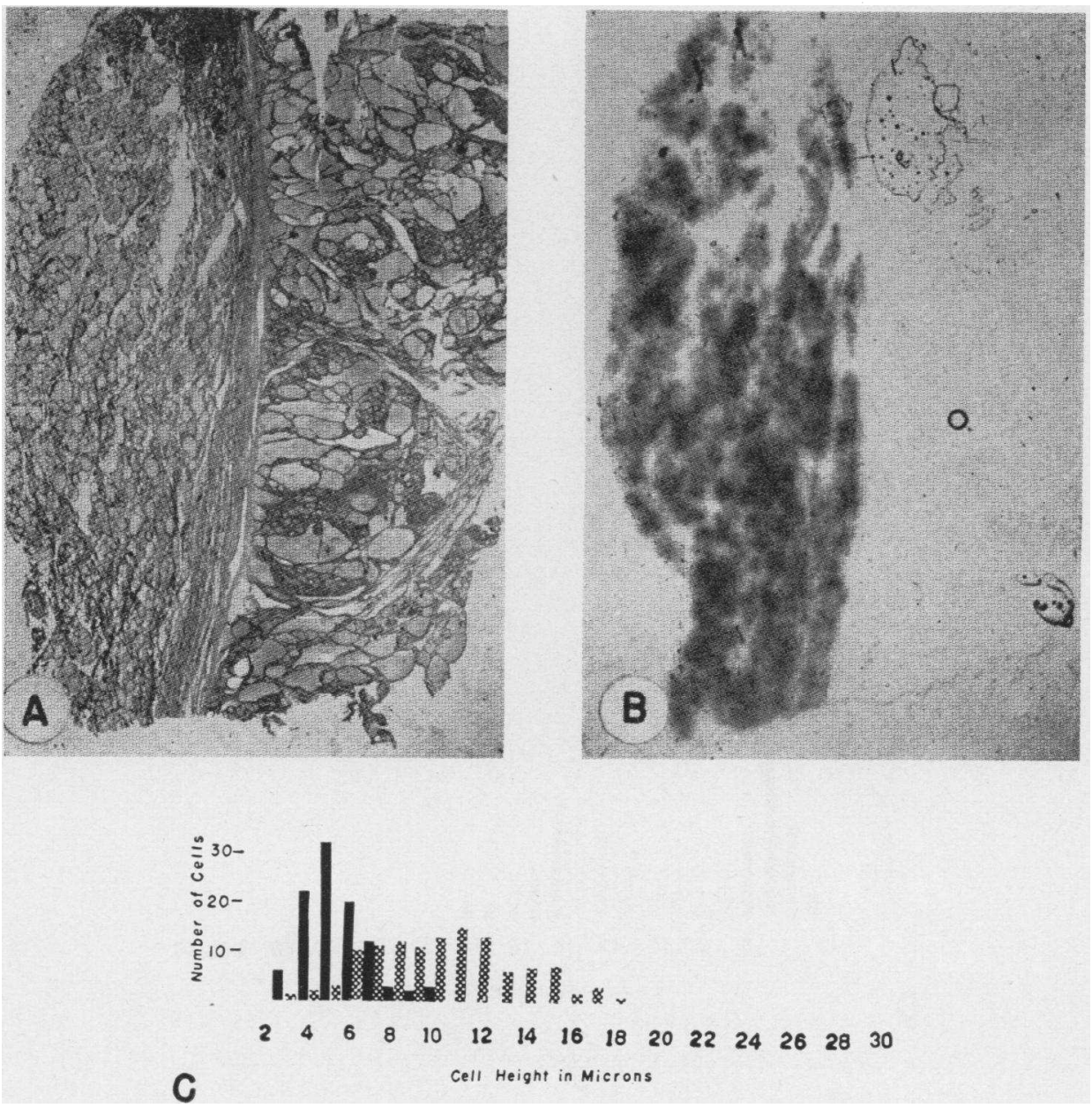

Fig. 5. Hyperplastic Adenoma without any Iodine Concentrating Function

A. Histologic section. Adenoma on right; extranodular tissue on left.

B. Autoradiogram showing that the radio iodine is concentrated in the extranodular tissue rather than in the adenoma.

C. Cell heights ( 100 cells in each type of tissue). Black columns represent the cells in the extranodular tissue; checkered cells represent the cells in the adenoma, showing an increased mean cell height but with considerable variability.

(From Dobyns and Lennon, J. Clin. Endocrinol., 1948, 8, 739.) 
radioautographic technics the capacity of certain cancers of the thyroid to accumulate radioactive iodine. They studied 19 selected cancers of the thyroid and observed that 10 of these tumors possessed the ability to accumulate radioactive iodine. Five of their functioning tumors presented the histologic structure of so-called "benign metastasizing struma." See Figure 7. The remaining five tu- mors which exhibited this evidence of function had the structure of follicular adenocarcinoma in some portion of the material studied. They concluded that pickup of iodine is closely linked with certain structural qualities, which include orderly cell arrangement in follicular pattern and the presence of colloid-like material. See Figure 8 .

Frantz et al. (43) in a study done on 32 cancers
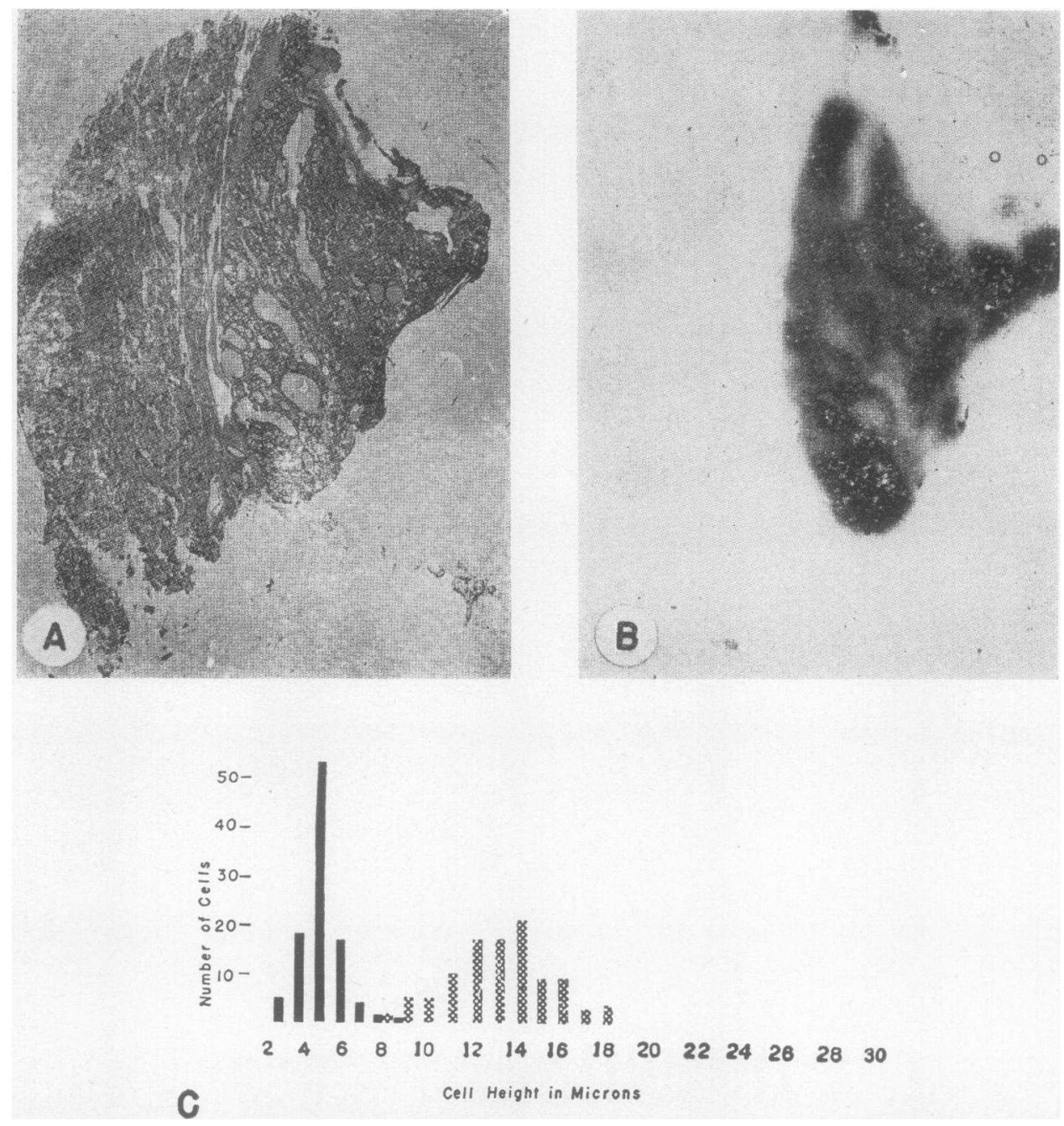

Fig. 6. Hyperplastic Adenoma with Hyperfunction

A. Histologic section. A roughly triangular piece of adenomatous tissue is shown on the right; uninvolved tissue on the left.

B. Autoradiogram showing the relatively high concentration of radio iodine in the adenoma and practically none in the remaining thyroid tissue. The adenoma is interpreted as being an adenoma functioning in excess of the remaining tissue.

C. Cell heights (100 cells in each type of tissue). Black columns represent the cells in uninvolved tissue; checkered columns represent cells of adenoma and illustrate the relative uniform cellular hypertrophy of hyperfunctioning thyroid adenomas.

(From Dobyns and Lennon, J. Clin. Endocrinol., 1948, 8, 737.) 
of the thyroid observed that seven out of 12 malignant adenomas and six mixed tumors picked up radio iodine. No pure papillary adenocarcinomas nor less differentiated cancers of the thyroid picked up the isotope.

Fitzgerald (44) reported before the Brookhaven conference that in a study of 47 selected cases of carcinoma of the thyroid given tracers of $\mathrm{I}^{131}$ prior to surgical removal, 20 cases showed retention of the radio iodine in some portion of the neoplastic areas. He reported that pure papillary adenocarcinomas of the thyroid did not retain the iodine. In five out of eight mixed papillary and follicular or alveolar adenocarcinomas, a retention of radio iodine was observed. He reported that two-thirds of the follicular and alveolar carcinomas stored radio iodine. Two cases of solid alveolar carcinoma stored the radioactive iodine. In six cases of Hurthle cell carcinoma and in two cases of spindle and giant cell carcinoma he found no storage of radio iodine.

Seidlin et al. (45) reported that eight out of 14 patients having cancer of the thyroid were capable of collecting radio iodine. They reported that the destruction of normal thyroid tissue by radioactive iodine resulted in an increased avidity for iodine by the cancer tissue in two of three patients. They also reported that one out of two patients treated with thyroid-stimulating hormone showed an increased pickup of iodine.

Rawson et al. (46) have observed the effect of thyroidectomy, surgical or by large doses of radio iodine, in 21 patients having relative or absolute non-functioning metastatic thyroid cancer. Following removal or destruction of the normal thyroid eight solid and/or alveolar adenocarcinomas assumed the capacity to concentrate radioactive iodine.

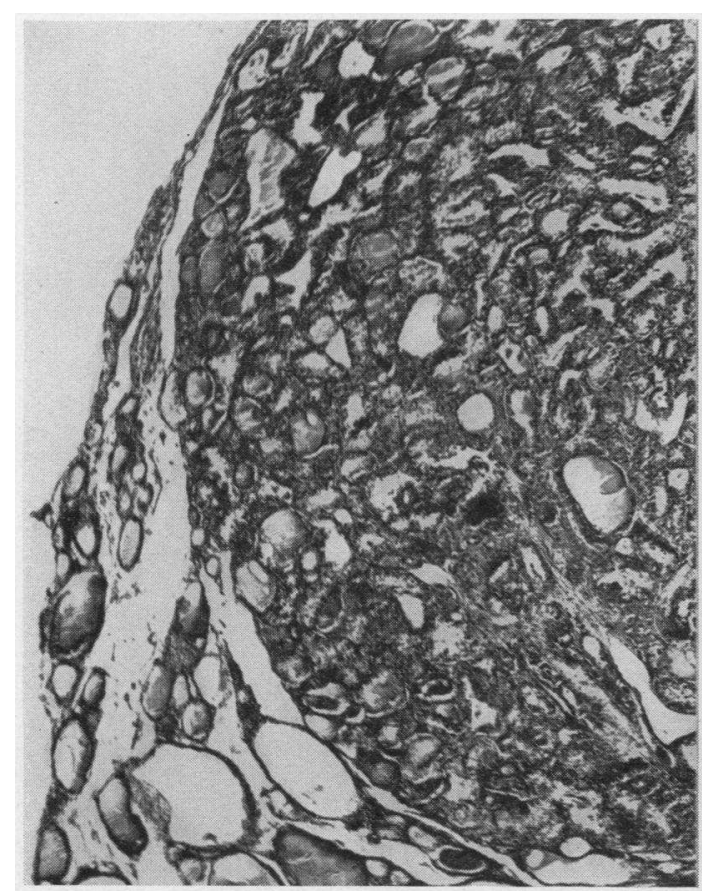

A

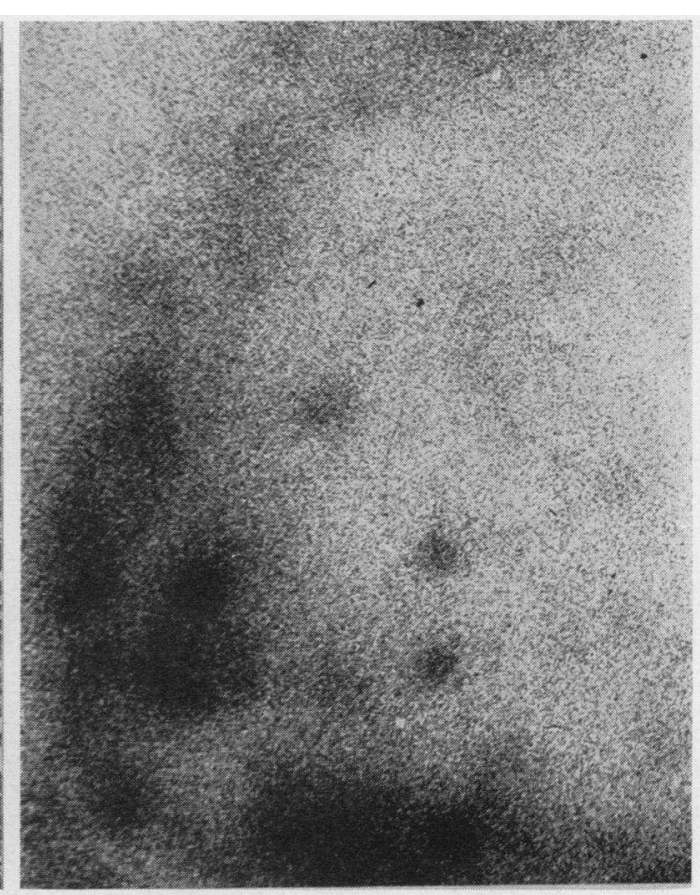

B

Fig. 7. Microfollicular Adenocarcinoma of the Thyrold Surrolnded by a Few Apparently Normal Thyroid Follicles

A. Histologic section.

B. Autoradiogram made by applying this section on photographic film. It would be noted that the maximum function is demonstrated in the uninvolved normal thyroid tissue. It will also be noted that the tumorous tissue concentrated significant amounts of radioactive iodine, but much less than that concentrated by the normal thyroid tissue.

(From Marinelli, Foote, Hill, and Hocker, Am. J. Roent., 1947,58, 26.) 
A case history of the first patient in whom they tried this experiment is quoted from their report:

"Mrs. T. I., M. G. H., number 48114, aged 43; was the first patient in whom this experiment was tried. She was admitted to the Massachusetts General Hospital on February 28, 1945, complaining of a soft tissue mass in the skull and of regrowth of a goiter. She gave a history of having had surgical removal in 1933 of a thyroid nodule which had existed for five years. She reported that one year before admission to this clinic she had first noted a lump over the occiput, and that six months before admission she had noted an extensive regrowth of her goiter. She was found to have a lemon-sized, moderately firm mass in the left occipitoparietal area measuring about $5 \times 6 \mathrm{~cm}$. in diameter and raised about $2 \mathrm{~cm}$. above the rest of the skull. She was also found to have a walnutsized, hard mass in the upper pole of the right lobe of the thyroid. Several large firm lymph nodes were palpable in the right anterior cervical chain. Clinically she was euthyroid and her basal metabolic rate was minus 12 per cent. X-ray studies of the chest and skeleton revealed only an osteolytic defect in the left parietal bone consistent with destruction by metastatic disease.
Tracer studies done with radioactive iodine revealed that the occipital metastasis was capable of concentrating only minimal amounts of iodine. It was reasoned that removal of her normal thyroid might be followed by a significant pickup of iodine by the skull metastasis. On March 6, 1945, Dr. R. R. Linton did a total thyroidectomy and a right radical neck dissection. At the same time a biopsy specimen was removed from the metastatic lesion in the skull. The thyroid showed a follicular adenocarcinoma. A similar picture was found in the small metastasis though this lesion showed more differentiation than the primary lesion and contained some colloid filled acini. Her normal thyroid was found to have collected 1.8 per cent of the preoperatively administered radioactive iodine per gram of tissue. The skull metastasis was found to have collected only 0.06 per cent of administered radio iodine per gram of tissue. On March 27, another tracer dose of radioactive iodine was administered and in vivo measurements over the metastatic lesion were made. Though the patient was found to concentrate less than 3 per cent of administered iodine in the skull metastasis, she did not develop myxedema in a period of four months. Indeed, in July 1945, her basal metabolic rate was plus 4 per cent. Hav-
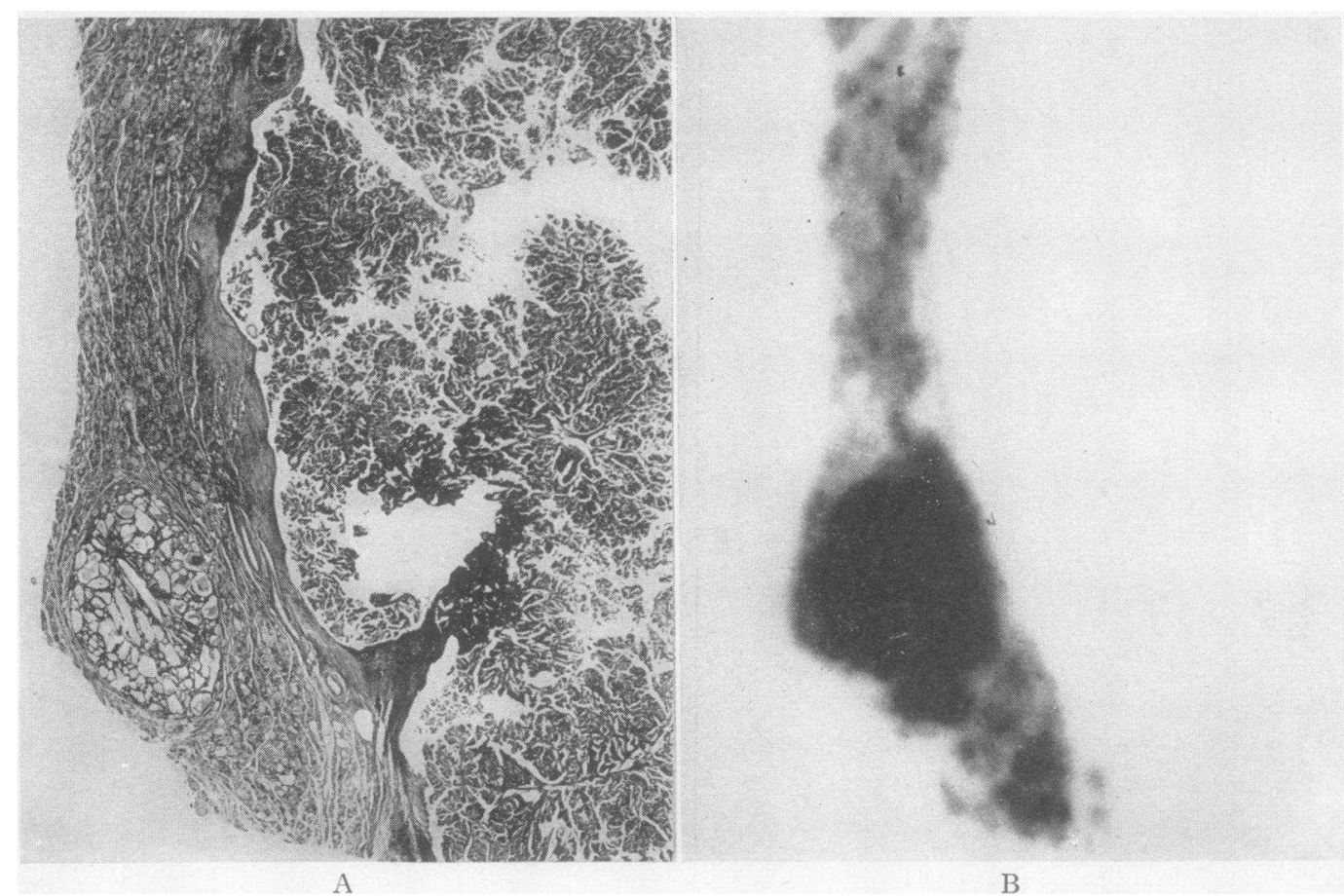

Fig. 8. Papillary Carcinoma of the Thyroid Surrounded by Uninvolved Thyroid Tissue

A. Histologic section of papillary carcinoma of the thyroid surrounded by uninvolved thyroid tissue and encapsulated micro et microfollicular adenoma.

B. Autoradiogram made by placing Section A on photographic film. It is to be noted that the cancerous tissue in this instance did not concentrate any radio iodine. It is of interest that the benign lesion in the extrathyroidal tissue is functional and indeed concentrated more iodine than did the surrounding uninvolved thyroid tissue.

(From Marinelli, Foote, Hill, and Hocker, Am. J. Roent., 1947, 58, 23.) 


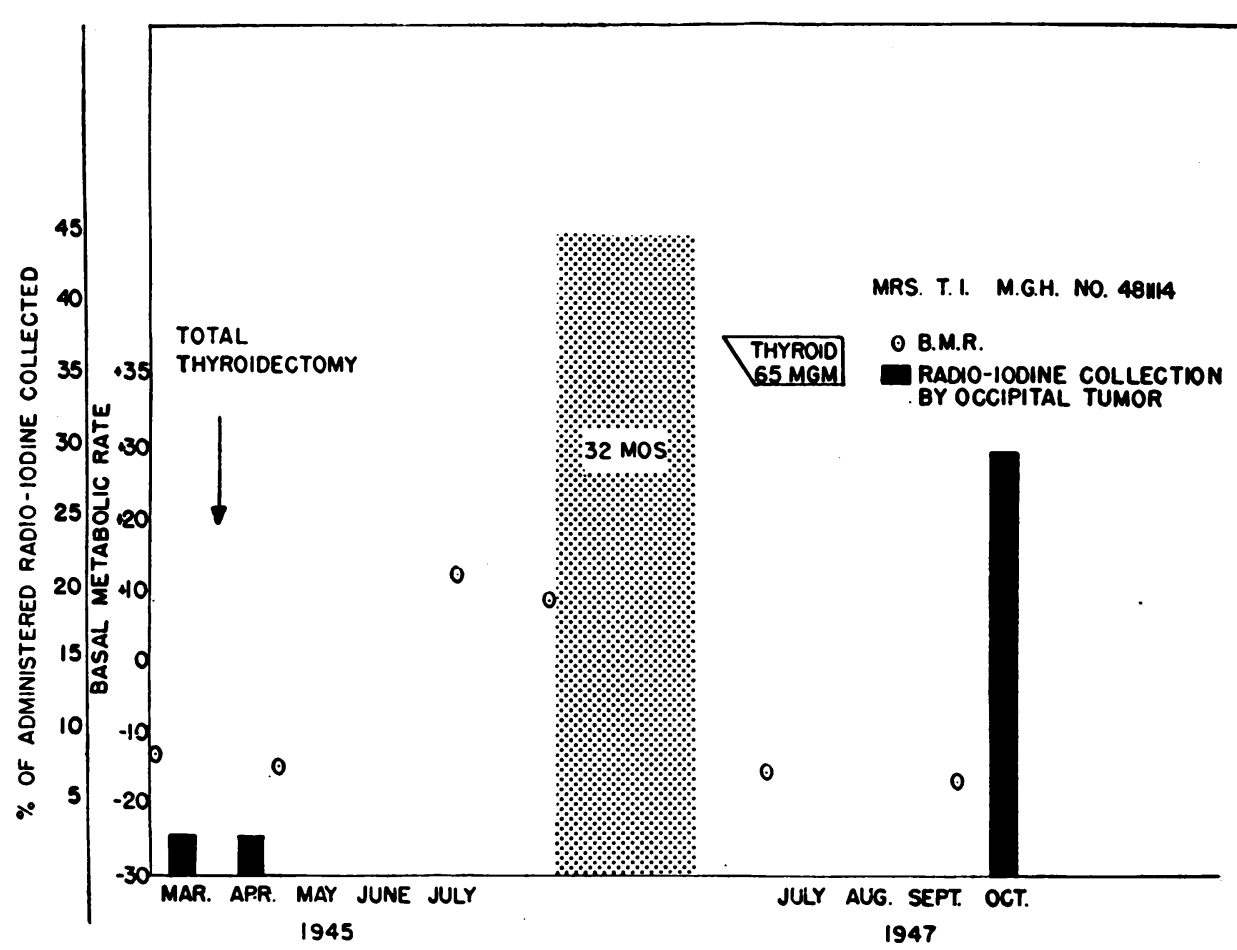

Fig. 9. B.M.R. Levels and Radio Iodine Collections by Metastatic Tumors Before and After Removal of the Normal Thyroid

It is to be noted that this patient concentrated considerably more radioactive iodine in her metastatic tumor after removal of the normal thyroid than she did before operation. It is also to be noted that four months after total removal of the normal thyroid her B.M.R. was within normal range. (From Rawson, Marinelli, Skanse, Trunnell and Fluharty, J. Clin. Endocrinol., 1948, 8, 832.)

ing the erroneous impression that thyroidectomy was ineffective in altering the function of this tumor, it was decided to attempt removal of the skull metastasis. On July 6, Dr. Mixter made this attempt. However, it was impossible to do more than a partial removal of the tumor. Postoperatively the patient was treated with $\mathrm{x}$-ray and received 1550 roentgens delivered in six doses through a $10 \times 10$ field. The patient returned to her home in Rochester, New York, and was not seen again until July of 1947. At that time she was taking desiccated thyroid in a daily dose of $65 \mathrm{mgm}$. (1 grain). She reported that in April of 1947 she had noted a regrowth of the tumor in her occipitoparietal area. She was found to have a moderately firm tumor, which measured about $2 \mathrm{~cm}$. in diameter, at the site of the previous occipital tumor. She had a basal metabolic rate of minus 16 per cent. A tracer dose of radioactive iodine was given on July 3, of which she excreted 92 per cent in the urine. In vivo measurements revealed radioactivity in the skull lesion and in the neck. There was about three times as much activity in the skull metastasis as in the neck. On August 1, she was advised to stop taking thyroid. She was readmitted to the hospital in October of 1947 and was found to have a B.M.R. of minus 11 per cent. Studies revealed an increase in size of the occipital lesion and a new osteolytic lesion in the third dorsal vertebral body. A tracer dose of radioactive iodine was administered on October 6 . Of this tracer dose, she excreted only 48 per cent. By in vivo measurements, it was estimated that she concentrated 30 per cent of the administered dose in her occipital lesion, 10 per cent in the region of her thyroid and 10 per cent in the vertebral lesion. This patient is now being treated with large doses of radioactive iodine." See Figure 9.

The time required to observe these changes subsequent to thyroidectomy varied between one month and 32 months. In four cases of pure papillary adenocarcinoma that they studied, total thyroidectomy had no effect on the function of previously non-functioning metastasis. These same investigators have likewise reported that the avidity for radio iodine of certain functioning cancers of the thyroid can be increased by administering thyroid-stimulating hormone. They have also observed that prolonged treatment with thiouracil may be followed by considerable increase in the 
iodine accumulating capacity of certain functioning cancers of the thyroid. This described effect of prolonged treatment with thiouracil might be ascribed to an increased elaboration and augmentation in action of the patient's own thyroid-stimulating hormone.

These observations in which it has been demonstrated that the function of metastatic cancer of the thyroid can be altered by removal of the normal thyroid or by administering thyroid-stimulating hormone suggest that this cancer is not wholly autonomous but is capable of responding to certain physiologic stimuli. They also provide us with concepts which may lead to a more complete understanding of the biology of this type of a neoplasm. It is hoped that these concepts may also be applied in studying neoplasms of other tissues as well.

In the light of present knowledge, our understanding as to the mechanisms through which the thyroid hormone exerts its actions on the cells of the body is a void. Recent studies, however, indicate that tracing labelled thyroid hormone through its circuit may throw some light on the mode of action of this hormone. Gross and LeBlond (47) have observed that thyroxine labelled with $\mathrm{I}^{131}$ when administered to intact rats is withdrawn from the blood stream and is demonstrable in various tissues within two hours of its administration. They also observed that it is broken down within the body to diiodotyrosine and iodide. Hamilton, 1948 (48) and Keating and Albert (49) have observed the fate of radio iodine labelled thyroxine, thyroglobulin and iodinated casein in myxedematous patients. They have observed that less than 5 per cent of the labelled iodine is excreted in the feces and that the rest is excreted in the urine. They have found that more than 90 per cent of the labelled iodine excreted in the urine is excreted as iodide and that the remainder is excreted as diiodotyrosine. One might suggest on the basis of these studies that the thyroid hormone in the process of exerting its action is broken lown and the iodine liberated to be excreted or utilized in the synthesis of thyroid hormone. It is to be hoped that these studies are only the beginning of investigations which may elucidate the mode of action of the thyroid hormone.

\section{SUM MARY}

1. Studies with radioactive iodine have resulted in major contributions to our knowledge of thyroid physiology, normal and morbid.

2. Thus far the completed studies are in harmony with previous observations made with the conventional biochemical technics. However, because of the fact that with these technics, physiologic levels of study never before obtained are possible, we have been able to broaden our knowledge of thyroid disease at a level which could not otherwise be reached.

3. With these technics we have been provided with better concepts as to

a. the actions of certain thyroid stimulators and inhibitors,

b. the function and biology of benign and malignant neoplasms of the thyroid,

c. a possible mode of action of the thyroid hormone on the tissues of the body.

4. It is suggested that these studies are only the beginning of new and intensive investigations on normal and morbid physiology of the thyroid which will not only lead to better understanding of thyroid disease but may also result in more intelligent and physiologic therapy of these maladies.

\section{BIBLIOGRAPHY}

1. Hertz, S., Roberts, A., and Evans, R. D., Radioactive iodine as an indicator in the study of thyroid physiology. Proc. Soc. Exper. Biol. \& Med., 1938, 38,510 .

2. Hamilton, J. G., Rates of absorption of radioactive isotopes of sodium, potassium, chlorine, bromine, and iodine in normal human subjects. Am. J. Physiol., 1938, 124, 667.

3. Hamilton, J. G., and Soley, M. H., Studies in iodine metabolism by the use of a new radioactive isotope of iodine. Am. J. Physiol., 1939, 127, 557.

4. LeBlond, C. P., and Sïe, P., Passage de l'iode radioactif $\left(f^{* 128}\right)$ dans la thyroide stimulée par l'hormone thyréotrope de l'hypophyse. Comp. rend. Soc. de biol., 1940, 133, 543.

5. Hamilton, J. G., and Soley, M. H., Studies in iodine metabolism of the thyroid gland in situ by the use of radio-iodine in normal subjects and in patients with various types of goiter. Am. J. Physiol., 1940, 131, 135.

6. Hamilton, J. G., Soley, M. H., Reilly, W. A., and Eichorn, K. B., Radioactive iodine studies in childhood hypothyroidism. Am. J. Dis. Child., 1943, 66, 495 . 
7. Hertz, S., Roberts, A., and Salter, W. T., Radioactive iodine as an indicator in thyroid physiology. IV. The metabolism of iodine in Graves' disease. J. Clin. Invest., 1942, 21, 25.

8. Chapman, E. M., Corner, G. W., Jr., Robinson, D., and Evans, R. D., The collection of radioactive iodine by the human fetal thyroid. J. Clin. Endocrinol., 1948 8, 717.

9. Astwood, E. B., and Stanley, M. M., Use of radioactive iodine in the study of thyroid function in man. West. J. Surg., 1947, 55, 625.

10. Keating, F. R., Jr., Power, M. H., Berkson, J., and Haines, S. F., The urinary excretion of radioiodine in various thyroid states. J. Clin. Invest., 1947, 26, 1138.

11. Quimby, E. H., and McCune, D. J., Uptake of radioactive iodine by the normal and disordered thyroid gland in children. Radiology, 1947, 49, 201.

12. McArthur, J. W., Rawson, R. W., Fluharty, R. G., and Means, J. H., The urinary excretion of radioactive iodine as an aid in the diagnosis of hyperthyroidism. Ann. Int. Med., 1948, 29, 229.

13. Feitelberg, S., Kaunitz, P. E., Wasserman, L. R., and Yohalem, S. B., The use of radioactive iodine in the diagnosis of thyroid disease. Am. J. Med. Sc., 1948, 216, 129.

14. Werner, S. C., Quimby, E. H., and Schmidt, C., The clinical use of radioactive iodine., Bull. N. Y. Acad. Med., 1948, 24, 549.

15. Werner, S. C., Quimby, E. H., and Schmidt, C., Clinical experience in diagnosis and treatment of thyroid disorders with radioactive iodine (eightday half-life). Radiology, 1948, 51, 564.

16. Skanse, B. N., and Riggs, D. S., Thyrotoxicosis factitia (alimentary thyrotoxicosis), its differentiation from spontaneous thyrotoxicosis with the aid of radioactive iodine. J. Clin. Endocrinol, 1948, 8, 532 .

17. Rawson, R. W., and Skanse, B. N., Radioactive iodine: its use as a tool in studying thyroid physiology. Radiology, 1948, 51, 525.

18. Stanley, M. M., and Astwood, E. B., The response of the thyroid gland in normal human subjects to the administration of thyrotropin as shown by studies with $\mathrm{I}^{131}$. Endocrinology, 1949, 44, 49.

19. Keating, F. R., Jr., Rawson, R. W., Peacock, W., and Evans, R. D., Collection and loss of radioactive iodine compared with anatomic changes induced in thyroid of chick by injection of thyrotropic hormone. Endocrinology, 1945, 36, 137.

20. Cortell, R., and Rawson, R. W., The effect of thyroxin on the response of the thyroid gland to thyrotropic hormone. Endocrinology, 1944, 35, 488.

21. Rawson, R. W., Hertz, S., and Means, J. H., Thiocyanate goiter in man. Ann. Int. Med., 1943, 19, 829.

22. Haines, S., Personal communication.

23. Richards, C. E., Brockhurst, R. J., and Coleman, T. H., Thiocyanate goiter with myxedema. Re- port of two cases. J. Clin. Endocrinol., 1949, 9, 446.

24. Rawson, R. W., Evans, R. O., Means, J. H., Peacock, W. C., Lerman, J., and Cortell, R. E., The action of thiouracil upon the thyroid gland in Graves' disease. J. Clin. Endocrinol., 1944, 4, 1.

25. Stanley, M. M., and Astwood, E. B., The accumulation of radioactive iodine by the thyroid gland in normal and thyrotoxic subjects and the effect of thiocyanate on its discharge. Endocrinology, 1948, 42, 107.

26. Stanley, M. M., and Astwood, E. B., Determination of the relative activities of antithyroid compounds in man using radioactive iodine. Endocrinology, 1947, 41, 66.

27. Rawson, R. W., McGinty, D. A., Peacock, W., Merrill, P., Wilson, M., and Lockhart, H., The effect of certain goitrogenic drugs on the absorption of radioactive iodine by the thyroid gland of rats and chicks. I. Collection of radioiodine by thyroids made goitrous following chronic administration of these agents. J. Pharmacol. and Exper. Therap., 1948, 93, 240.

28. McGinty, D. A., Rawson, R. W., Fluharty, R. G., Wilson, M., Riddell, C., and Yee, H., The effect of certain goitrogenic drugs on the absorption of radioactive iodine by the thyroid gland. II. Collection of radioiodine by thyroids of rats and chicks following a single injection of these agents. J. Pharmacol. and Exper. Therap., 1948, 93, 246.

29. McGinty, D. A., and Wilson, M., Comparative activity of thiouracil and other antithyroid compounds in the rhesus monkey. In press.

30. Plummer, H. S., Results of administering iodine to patients having exophthalmic goiter. J. A. M. A., 1923, 80, 1955.

31. Rawson, R. W., Moore, F. D., Peacock, W., Means, J. H., Cope, O., and Riddell, C. B., Effect of iodine on the thyroid gland in Graves' disease when given in conjunction with thiouracil. A two-action theory of iodine. J. Clin. Invest., 1945, 24, 869.

32. Wolff, J., and Chaikoff, I. L., Plasma inorganic iodide as a homeostatic regulator of thyroid function. J. Biol. Chem., 1948, 174, 555.

33. Greer, M. A., and Astwood, E. B., The antithyroid effect of certain foods in man as determined with radioactive iodine. Endocrinology, 1948, 43, 105.

34. Cope, O., Rawson, R. W., and McArthur, J. W., The hyperfunctioning single adenoma of the thyroid. Surg., Gynec. and Obst., 1947, 84, 415.

35. Rawson, R. W., McArthur, J. W., Dobyns, B. M., Fluharty, R. G., and Cope, O., The functional activity of thyroid tumors benign and malignant as gauged by their collection of radioactive iodine. West. J. Surg., 1948, 56, 82.

36. Dobyns, B. M., and Lennon, B., A study of the histopathology and physiologic function of thyroid tumors, using radioactive iodine and radioautography. J. Clin. Endocrinol., 1948, 8, 732. 
37. Hamilton, J. G., Soley, M. H., and Eichorn, K. B., Deposition of radioactive iodine in human thyroid tissue. Univ. California Publ. Pharmacol. (no. 28) $1940,1,339$.

38. Keston, A. S., Ball, R. P., Frantz, V. K., and Palmer, W. W., Storage of radioactive iodine in metastasis from thyroid carcinoma. Science, 1942, 95, 362.

39. Frantz, V. K., Ball, R. P., Keston, A. S., and Palmer, W. W., Thyroid carcinoma with metastases, studied with radioactive iodine. Ann. Surg., 1944, 119, 668.

40. Leiter, L., Seidlin, S. M., Marinelli, L. D., and Baumann, E. J., Adenocarcinoma of the thyroid with hyperthyroidism and functional metastases. I. Studies with thiouracil and radio-iodine. J. Clin. Endocrinol., 1946, 6, 247.

41. Seidlin, S. M., Marinelli, L. D., and Oshry, E., Radioactive iodine therapy. Effect on functioning metastases of adenocarcinoma of the thyroid. J. A. M. A., 1946, 132, 838.

42. Marinelli, L. D., Foote, F. W., Hill, R. F., and Hocker, A. F., Retention of radioactive iodine in thyroid carcinomas, histopathologic and radioautographic studies. Am. J. Roentgenol., 1947, 58, 17.
43. Frantz, V. K., Quimby, E. H., and Evans, T. C. Radioactive iodine studies of functional thyroid carcinoma. Radiology, 1948, 51, 532.

44. Fitzgerald, P. J., Histologic types of thyroid carcinoma and their respective abilities to store radioactive iodine ${ }^{\mathbf{1 3 1}}$ as demonstrated by radioautograms. Brookhaven National Laboratory, Brookhaven Conference Report, Radioiodine, July 28-30, 1948.

45. Seidlin, S. M., Oshry, E., and Yalow, A. A., Spontaneous and experimentally induced uptake of radioactive iodine in metastases from thyroid carcinoma: a preliminary report. J. Clin. Endocrinol., 1948, 8, 423.

46. Rawson, R. W., Marinelli, L. D., Skanse, B. N., Trunnell, J. B., and Fluharty, R. G., The effect of total thyroidectomy on the function of metastatic thyroid cancer. J. Clin. Endocrinol., 1948, 8, 826.

47. Gross, J., and Leblond, C. P., Distribution of a large dose of thyroxine labeled with radioiodine in the organs and tissues of the rat. J. Biol. Chem., 1947, 171, 309.

48. Hamilton, C. F., Radioactive iodocasein: its action, fate and distribution in the human. Tr. Am. Goiter A., 1948, p. 3.

49. Keating, F. R., Jr., and Albert, A. In press. 